Dario De Fidio

Vittorio Sciruicchio

Beatrice Pastore

Maria Pia Prudenzano

Elisa Di Pietro

Alfonso Tramontano

Angelo Lorizio

Franco Granella

Gennaro Bussone

Licia Grazzi

Paola Sarchielli

\section{Chronic daily headache: personality study by means of computerized MMPI-2}

D. De Fidio (可)

Neurological Clinic I, Policlinico,

University of Bari,

Piazza Giulio Cesare 11, I-70124, Bari, Italy

e-mail: f.m.puca@neurol.uniba.it

Tel.: +39-080-5592331

Fax: +39-080-5478532

The affiliations of the other authors are listed at the end of the article

\begin{abstract}
Unresolved questions in headache research are the roles of drug abuse and psychopathology in headache disorder, especially in chronic daily headache. We investigated the utility of the revised version of the Minnesota Multiphasic Personality Inventory (MMPI-2) for assessing psychopathology in chronic daily headache patients. Chronic headache sufferers gave characteristic responses on Hy (hypochondria), D (depression) and Hs (hysteria) scales which are known as the "neu-
\end{abstract}

rotic triad". Although our data suggest that the MMPI profile types do not discriminate between different diagnosis groups and fail to determine whether psychopathological traits predispose to drug abuse, they nonetheless confirm the importance of psychological assessment as an essential step in the decision to seek medical help for headache.

Key words MMPI-2 • Chronic daily headache $\cdot$ Personality inventory

\section{Introduction}

Unresolved questions in headache research are the roles of drug abuse and psychopathology in headache disorders, especially in chronic daily headache. Multiple psychophysiological measures and personality assessment techniques are used to facilitate the diagnosis of headache. The Minnesota Multiphasic Personality Inventory (MMPI) is the most widely used personality assessment and provides objective scoring [1].

In previous studies, pain patients showed characteristic "neurotic" MMPI profiles, with elevation of the first three clinical scales (Hy, hypochondriasis; D, depression; and Hs, hysteria) [2].

Ellersten [3] observed that the "psychosomatic V-configuration" was highest in the group with the most severe and intractable headache. Similar results were found in other non-cephalic pain syndromes [4].

Kudrow and Sutkus [5] found that patients with migraine and cluster headache scored lowest, those with tension-type headache (TTH) and "combination headache" scored in the intermediate range, and those with post-traumatic headache scored highest on the neuroticism scales of the MMPI [5].

Pfaffenrath et al. [6] studied 434 patients with migraine, tension-type headache, "mixed" headache, and cluster headache. The patients all had a statistically significant elevation of $\mathrm{Hs}, \mathrm{D}$, and Hy scales compared to test norms. There were no statistical differences between drug abusers and nonabusers in any of the four headache groups [6].

Mongini et al. [7], instead, found that patients with atypical facial pain had higher scores on "neurotic" scale and on several psychotic scales of the MMPI. On other hand, Costello et al. [8] did not find a "neurotic triad" but another subclinical profile. A previous study using computerized MMPI-1 carried out on 181 chronic daily headache patients subjects, coming from six Italian headache centers, confirmed the impairment on the first three scales [9].

The aim of this study was to investigate the utility of the 
revised version of the Minnesota multiphasic personality inventory, the MMPI-2, for assessing psychopathology in chronic daily headache patients.

\section{Subjects and methods}

The patient sample consisted of 50 subjects (12 men and 38 women). The mean age of the participants was 39.96 years $(\mathrm{SD}=$ 14.97). Mean age at headache onset was 23.24 years $(\mathrm{SD}=12.37$ ), while duration of chronic illness was 5.98 years $(\mathrm{SD}=7.49)$. The demographic details of the sample are listed in Table 1. All patients had a headache frequency of at least 15 attacks for months and were classified into three types of daily headache: chronic tension-type headache $(\mathrm{CTTH})$, chronic coexisting migraine with tension-type headache $(\mathrm{CCMTTH})$ and chronic migraine $(\mathrm{CM})$. Moreover, we identified analgesic overuse by mean of a specific form proposed by the Modena Headache Center. The Italian version of the MMPI-2 was used [10]. MMPI-2 is a 567-item true-false questionnaire that describes a patient on 3 validity and 10 clinical scales. In addition to a restandardization of the clinical scales from the original MMPI (the new version presents some items added to the 506 items of the old version and some of them have been deleted), the MMPI-2 yields 15 additional "content scales" and 59 supplementary scales and subscales. For each scale and subscale, a T-score of 65 is considered to be the level of clinical significance (the $95^{\text {th }}$ percentile). The scoring and the data interpretation were performed by means of an automated system ideated by Pancheri et al. [11] (MMPI2-Panda) and incorporates Welsh's code-types and Diamond's bipolar axes method. The occurrence of T-score $\geq 65$ in the validity and clinical scales was calculated and analyzed according to gender and drug abuse by means of the Mantel-Haenszel chi square test.

\section{Results}

A T-score $\geq 65$ was observed on the Hs scale $(76 \%$ of the cases, mean value $71.6 \pm 10.44$ ), on D scale ( $58 \%$ of the cases, mean value $67.58 \pm 12.73$ ) and on Hy scale (54\% of the cases, mean value $66.10 \pm 10.66$ ) (Fig. 1). No statistical difference was found according to either gender or drug abuse.

When considering the selection of Harris-Lingoes subscales [12], a T-score $\geq 65$ was found in over $50 \%$ of patients on subscales D1 (subjective depression) and D3 (physical malfunctioning) (Fig. 2).

Table 1 Demographic characteristics of the 50 patients

Patients

Women, $\mathrm{n}(\%)$

Drug abusers, n $(\%)$

$38 \quad(76)$

Mean age (SD), years

Education (SD), years

Mean age at headache onset (SD), years

Mean age at chronic headache onset (SD), years

Mean chronic headache duration (SD), years

a Range, 18-65 years

Fig. 1 MMPI-2 profile in 50 chronic daily headache patients. $L$, Lie; $F$, frequency; $K, \mathrm{~K}$-correction; $H s$, hypocondrias; $D$, depression; Hy, hysteria;

$P d$, psychopatic deviate; $M f$, mascolinityfemininity; $P a$, paranoia; $P t$, psychasthenia; $S c$, schizofrenia; $M a$, hypomania; $S i$, social introversion

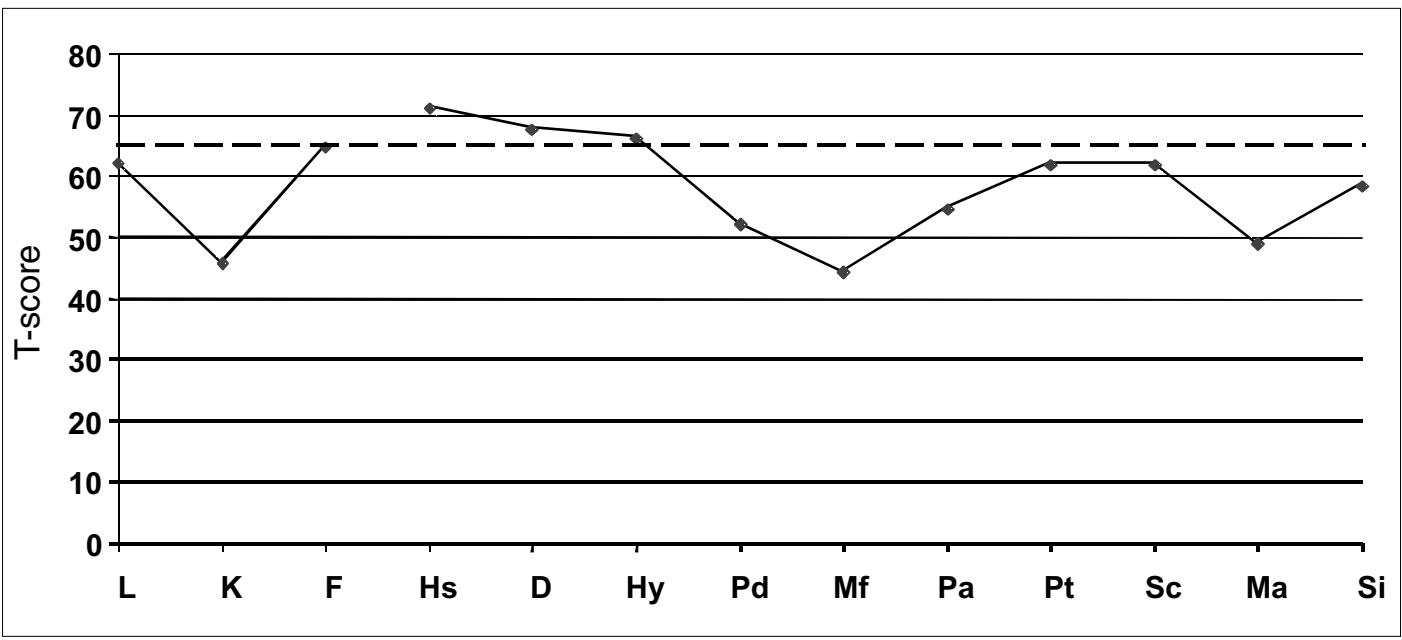


Fig. 2 Prevalence of patients with T-score $>65$ on MMPI-2 HarrisLingoes depression subscales. $D 1$, subjective depression; $D 2$, psychomotor retardation; $D 3$, physical malfunctioning; $D 4$, mental dullness; $D 5$, brooding

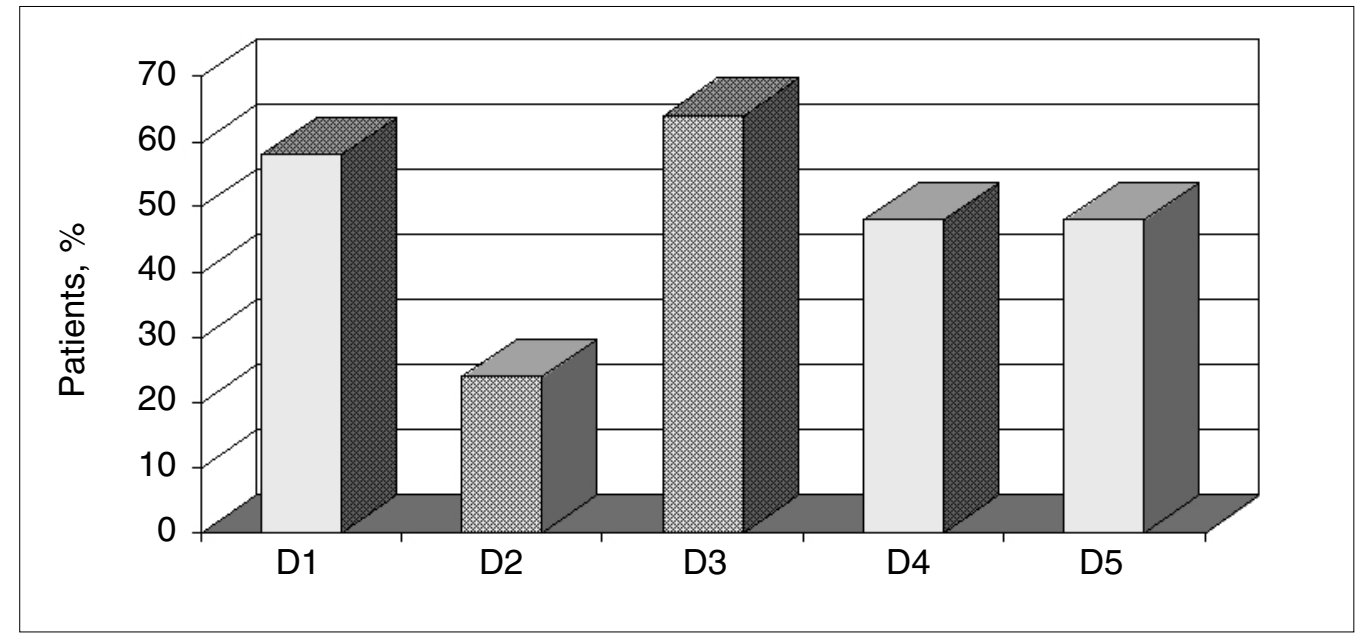

No statistical difference was observed between abusers and nonabusers. Concerning subscales of scale 3 (hysteria) a T-score $\geq 65$ emerged in Hy3 (lassitude-malaise) and Hy4 (somatic complaints) (Fig. 3)

The evaluation of content scales showed higher scores in anxiety (42\%, mean T-score 61.58 \pm 12.00 ), depression
(50\%, mean T-score 65.68 \pm 14.69$)$, health concerns (66\%, mean T-score 70.86 \pm 12.68$)$, type-A behavior (30\%, mean Tscore $60.58 \pm 10.65)$, work interference $(42 \%$, mean T-score $63.32 \pm 12.40)$, negative treatment indicator $(54 \%$, mean $\mathrm{T}$ score $65.76 \pm 13.39$ ), and family problems (28\%, mean Tscore $52.00 \pm 15.53$ ) (Fig. 4). Any significant difference in

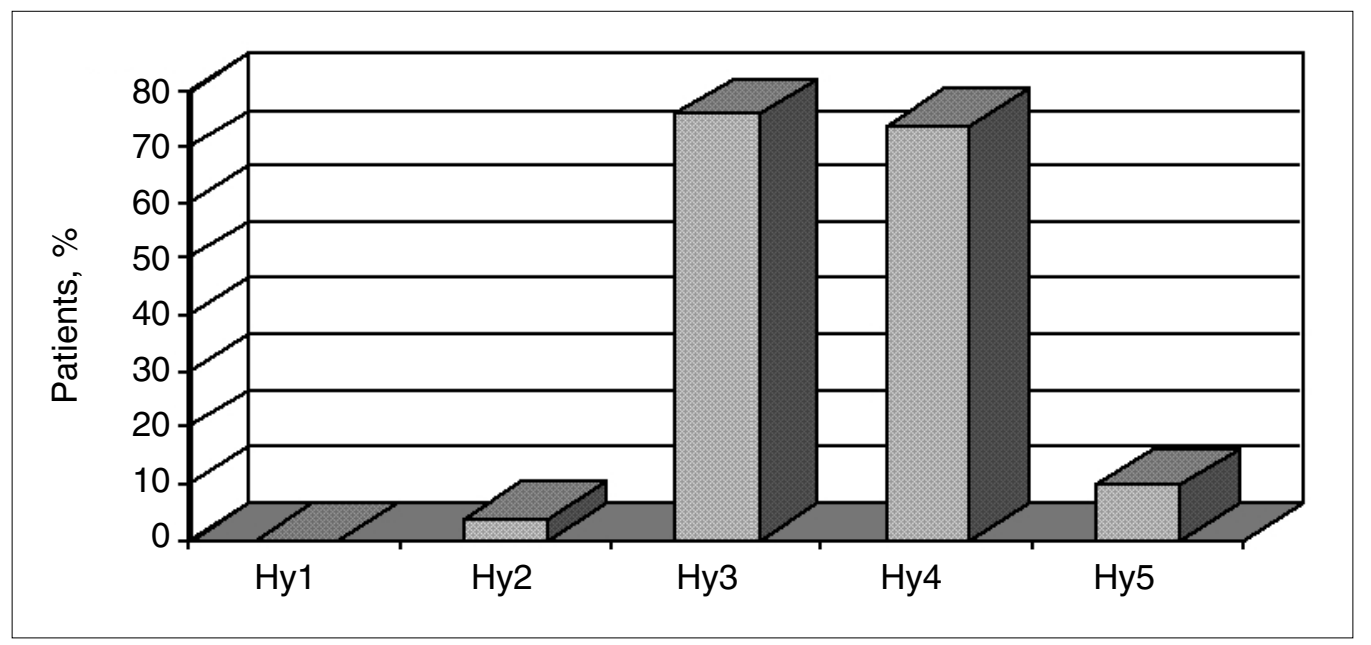

Fig. 3 Prevalence of patients with T-score $\geq 65$ on MMPI-2 HarrisLingoes depression subscales. Hyl, denial of social anxiety; $H y 2$, need for affection; $H y 3$, lassitude-malaise; $H y 4$, somatic complaints; $H y 5$, inhibition of aggression

Fig. 4 Prevalence of patients with T-score $\geq 65$ on MMPI-2 content scale. $A N X$, anxiety; $F R S$, fears; $O B S$, obsessiveness; $D E P$, depression; $H E A$, health concerns; $B I Z$, bizarre mentation; $A N G$, anger; $C Y N$, cynicism; $A S P$, antisocial practices; TPA, type-A behavior (hypermotivation, impatience and irritability); LSE low self-esteem; $S O D$, social discomfort; FAM, family problems; WRK, work interference; $T R T$, negative treatment indicator

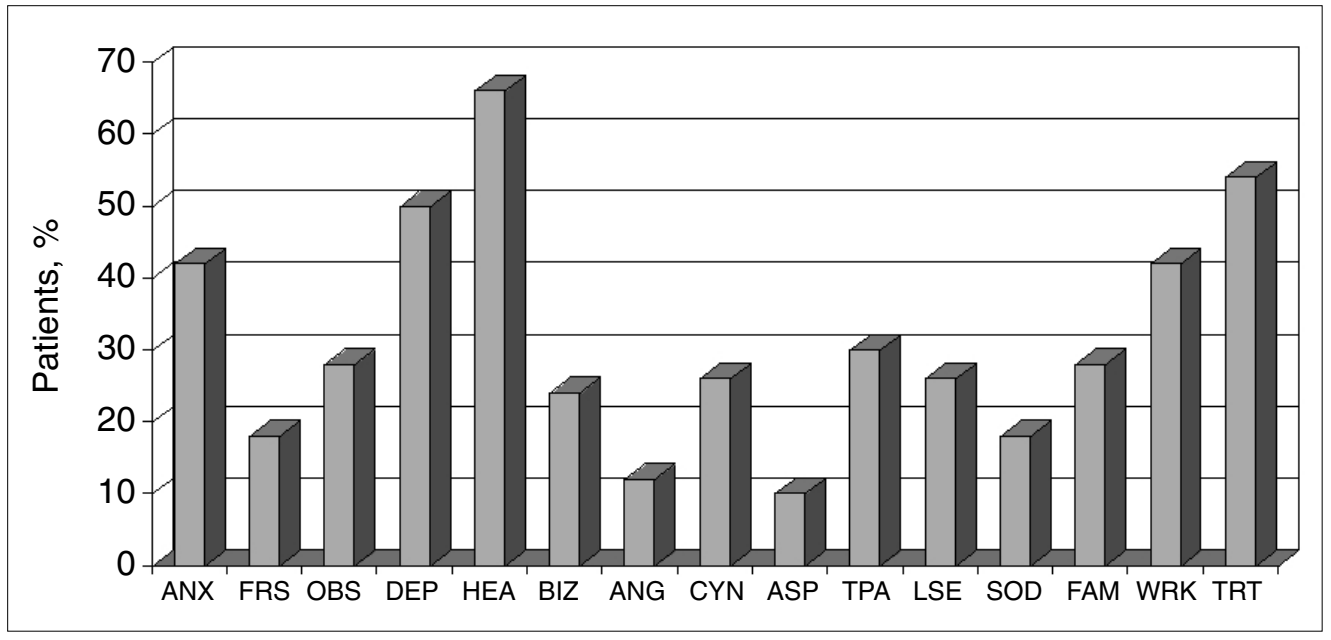


psychological state emerged between genders, among the different chronic headache types at observation time (chronic tension-type headache, chronic migraine and chronic coexisting migraine and tension-type headache) and between abusers and nonabusers.

\section{Discussion}

Chronic headache sufferers gave characteristic responses on the hypochondria, depression and hysteria scales which are known as the "neurotic triad". This result was confirmed by the scores on the Harris-Lingoes subscales and is in agreement with previous studies [2, 5-9].

No specific "headache personality" was found when comparing either the different chronic headache subtypes or the abusers and nonabusers. Besides, without prospective studies it is not possible to confirm if such a character's aspects are pre-existent to the first appearance of the disease or are a reflection of distress related to the pain problem.

Although our data suggest that the MMPI profile types do not discriminate between different diagnosis groups and fail to determine whether psychopathological traits predis- pose to drug abuse, they nonetheless confirm the importance of psychological assessment as an essential step in the decision to seek medical help for headache.

V. Sciruicchio $•$ B. Pastore $•$ M.P. Prudenzano

Neurological Clinic I,

University of Bari, Bari, Italy

E. Di Pietro • A. Tramontano

Villa degli Ulivi, Caserta, Italy

A. Lorizio

U.O. Neurologia P.O.

Bassano del Grappa (VI), Italy

F. Granella

Neurological Clinic,

University of Parma, Parma, Italy

G. Bussone • L. Grazzi

C. Besta National Neurological Institute, Milan, Italy

P. Sarchielli

Neurological Clinic,

University of Perugia, Perugia, Italy

\section{References}

1. Hathaway SR, McKinley JC (1943)

The Minnesota Multiphasic Personality Inventory. University of Minnesota Press, Minneapolis

2. Mathew N, Stubits E, Nigam MP (1982) Tranformation of episodic migraine into daily headache: analysis of factors. Headache 22:66-68

3. Ellersten B (1991) Personality factors in recurring and chronic pain. Cephalalgia 12:129-132

4. Ellersten B, Klove H (1987) MMPI patterns in chronic muscle pain, tension headache and migraine, Cephalalgia 7:65-71

5. Kudrow L, Sutkus BJ (1979) MMPI pattern specificity in primary headache disorders. Headache 19:18-24
6. Pfanferrath W, Hammelsberger J, Pollmann W, Aube H, Rath M (1991) MMPI personality profiles in patients with primary headache syndromes. Cephalalgia 11(6):263-268

7. Mongini F, Ferla E, Maccagnani C (1992) MMPI profiles in patients with headache or craniofacial pain: a comparative study. Cephalalgia 12:91-98

8. Costello R, Hulsey T, Schoenfeld L, Ramamurthy S (1987) P-A-I-N: a four cluster MMPI typology for chronic pain. Pain 30:199-209

9. Puca F, Genco S, Prudenzano MP, Sciruicchio V Pastore B, Relja G, Nider G, Bussone G, Grazzi L, Libro G, Di Pietro E, Tramontano A, Marzo A, Granella F, Schianchi C, De Fidio D (1997) Psychopathological aspects of chronic primary headache: a multicentric study by means of MMPI. Cephalalgia 17(3):285
10. Hathaway SR, McKinley JC (1995) Minnesota Multiphasic Personality Inventory 2 - Manuale. Organizzazioni Speciali, Florence (Italian translation, Pancheri P, Sirigatti S)

11. Pancheri P, De Fidio D (1999) Dal Minnesota Multiphasic Personality Inventory al "Panda": il MMPI-2 automatico. Giornale Italiano di Psicopatologia 5(2):143-154

12. Harris RE, Lingoes JC (1955) Subscales for the MMPI: an aid to profile interpretation, mimeographed materials. Department of Psychiatry, University of California (Corrected version, 1948) 